\title{
Current prevalence of Opisthorchis viverrini infection and associated risk factors in Nakhon Phanom Province, Northeastern Thailand
}

\author{
Chuangchaiya, S. ${ }^{1 *}$, Navanesan, S. ${ }^{2}$, Jaichuang, S. ${ }^{3}$, Rahim, M.A.F.A. ${ }^{4}$ and Idris, Z.M. ${ }^{*}$ \\ ${ }^{1}$ Department of Community Health, Faculty of Public Health, Kasetsart University Chalermphrakiat Sakon \\ Nakhon Province Campus, Sakon Nakhon Province, 47000, Thailand \\ ${ }^{2}$ Secretariat for Medical Research and Innovation, Faculty of Medicine, Universiti Kebangsaan Malaysia \\ 56000, Kuala Lumpur, Malaysia \\ ${ }^{3}$ Nakhon Phanom Provincial Public Health Office, Muang District, Nakhon Phanom Province, 48000, Thailand \\ ${ }^{4}$ Department of Parasitology and Medical Entomology, Faculty of Medicine, Universiti Kebangsaan Malaysia, \\ 56000, Kuala Lumpur, Malaysia \\ *Corresponding author e-mails: sriwipa.c@ku.th; zulkarnain.mdidris@ukm.edu.my \\ Received 18 May 2020; received in revised form 17 September 2020; accepted 20 September 2020
}

\begin{abstract}
Opisthorchiasis caused by Opisthorchis viverrini infection is a major public health concern in Thailand. Despite many decades of national campaigns in place to reduce and control opisthorchiasis in Thailand, the infections remain to exist particularly in the northern and northeastern parts of the country. This study aimed to evaluate the current prevalence of $O$. viverrini infection in rural communities in northeast Thailand. A cross-sectional survey was conducted between February and October 2018 in three districts (Na Kae, That Phanom and Wang Yang) in Nakhon Phanom Province, Thailand. Demographic data were collected using a standardised questionnaire. Stool samples were collected and processed using the Kato-Katz technique to determine the presence of $O$. viverrini and other intestinal parasites. In total, 564 individuals were enrolled. The overall intestinal helminth infections were $15.2 \%$ (95\% CI: 12.4-18.5). Species distribution included a majority of $O$. viverrini mono-infections (12.9\%), followed by Strongyloides stercoralis (1.4\%) and Taenia spp. (0.4\%). The prevalence of $O$. viverrini was significantly higher in Wang Yang district $(P=0.022)$, in males $(P=0.004)$ and those previously positive with helminth infections $(P<0.001)$ and received treatment of anti-helminths $(P<0.001)$, than in their counterparts. Multivariate regression analysis revealed that being male (adjusted odds ratio [aOR] 1.77, $P=0.035$ ) and those who previously tested positive for helminth infections (aOR 8.69, $P<0.001$ ) were significantly associated with a higher odd of $O$. viverrini infections, but lower in those who had previous stool examination (aOR $0.22, P=0.001$ ). This study demonstrated that the updated prevalence of $O$. viverrini infection is still high in rural communities in northeast Thailand. The data of this study will be useful to guide and improve strategies for future $O$. viverrini and other helminths prevention and control in this region.
\end{abstract}

\section{INTRODUCTION}

The incidence of neglected tropical diseases caused by intestinal parasites is an increasingly serious global health issue. A quarter of the world population suffers from at least one type of intestinal parasitic infection with approximately 450 million individuals believed to be a host for multiple parasitic species (Robertson et al., 2013).
Southeast Asian countries such as Myanmar, Vietnam and Laos do not escape from the wrath of these parasites, with Thailand being one of the most affected, particularly in the north-eastern region (Conlan et al., 2012; Songserm et al., 2012; Tun et al., 2013).

Among these intestinal parasites, the helminth Opisthorchis viverrini, or commonly known as the liver fluke, does seem to have a strong foothold in this region. 
An estimate of 8 to 10 million people in Thailand is infected with $O$. viverrini (Sithithaworn et al., 2012), with the northeastern region recording a higher prevalence when compared with the neighbouring provinces (Suwannatrai et al., 2018). O. viverrini, which was classified as Class 1 carcinogen by The International Agency for Research on Cancer (IARC) in 2009, is commonly associated with incidence of hepatobiliary diseases and the causative agents of bile duct cancer (cholangiocarcinoma) (Sripa et al., 2007; Bouvard et al., 2009; Laoraksawong et al., 2018). Infections by these intestinal helminths are rarely diagnosed at an early stage of exposure due to its asymptotic nature, exasperating the prevalence of opisthorchiasis in these regions (Kaewpitoon et al., 2018).

A continuous effort has been undertaken by the Ministry of Public Health to eradicated the persistent $O$. viverrini infection among the rural population in Thailand, such as the Eco-Health/One Health approach (Sripa et $a l ., 2015)$ and the Cholangiocarcinoma Screening and Care Programme (Khuntikeo et al., 2015). These programmes have had significant success, bringing down the national average infection rate to $9.4 \%$ in 2000 , further dropping to $8.7 \%$ in 2009 . However, the disease remains prevalent, especially in the north and north-eastern regions, being among the highest affected areas in the world (Sithithaworn et al., 2012).

Among the 20 provinces in Northeastern Thailand, Nakhon Phanom Province has consistently shown a high incidence of infection by these helminths (Thaewnongiew et al., 2014). Studies have shown an infection rate as high as $20 \%$ among communities in this province, with a substantial intensity of $O$. viverrini present among the cyprinid fish found in this region (Sithithaworn $e t$ al., 2012; Chuangchaiya et al., 2019). Through this study, we aimed to evaluate the current prevalence of $O$. viverrini infection in rural communities in Northeastern Thailand. Based on the data obtained through this cross-sectional study, we also sought to identify associated risk factors linked with the prevalence of $O$. viverrini present in the Nakhon Phanom Province.

\section{MATERIALS AND METHODS}

\section{Ethical approval}

This study was approved by the Ministry of Health of Thailand (reference no. 5/2560) and the Ethics Review Committee of the Sawang Dan Din Crown Prince Hospital (reference no. SWDCPH 2017-009). Informed consent was obtained from all the participants before they were enrolled in the study.

\section{Study area and sample population}

The study was carried out between February and October 2018 in three districts in Nakhon Phanom Province, Thailand namely Na Kae, That Phanom and Wang Yang (Figure 1). The three districts have a combined population of 175,515 people (Department of Provincial Administration, Thailand). The sample size for study participants was calculated using the following formula the Cochran's formula: $\mathrm{N}=\mathrm{z}^{2} \mathrm{p}(1-\mathrm{p}) / \mathrm{e}^{2}$, where $\mathrm{z}$ is the confidence interval which is set at 95\% (z-value of 1.96); $\mathrm{p}$ is the expected prevalence of $O$. viverrini infections of $40.9 \%$ for Nakhon Phanom (Thaewnongiew et $a l ., 2014$ ) and e is the allowed error margin which is set to $5 \%$. In addition, contingencies were adjusted by adding another $40 \%$ of individuals, giving us a minimum of 519 participants to be sampled.

Village leaders and household heads were informed about the study's objectives and procedures. A convenience sampling strategy was used in this study, whereby residents were asked to come to the selected survey point for study participation. Enrolled participants were interviewed using standardised questionnaires in Thai language to identify the risk factors for $O$. viverrini infection. The questionnaires covered socio-demographic aspects (i.e. age, gender, education level, marital status, occupation, income level, alcohol consumption as well as present and type of domestic animal) and history of behavioural aspects (i.e. raw fish consumption, type of fish consumption [Hampala dispar, Osteochilus vittatus, Barbonymus gonionotus and Anematichthys apogon], open defecation, previous stool examination, the positivity of helminth infection, anthelminthic drug intake and prior knowledge about $O$. viverrini infection). All 


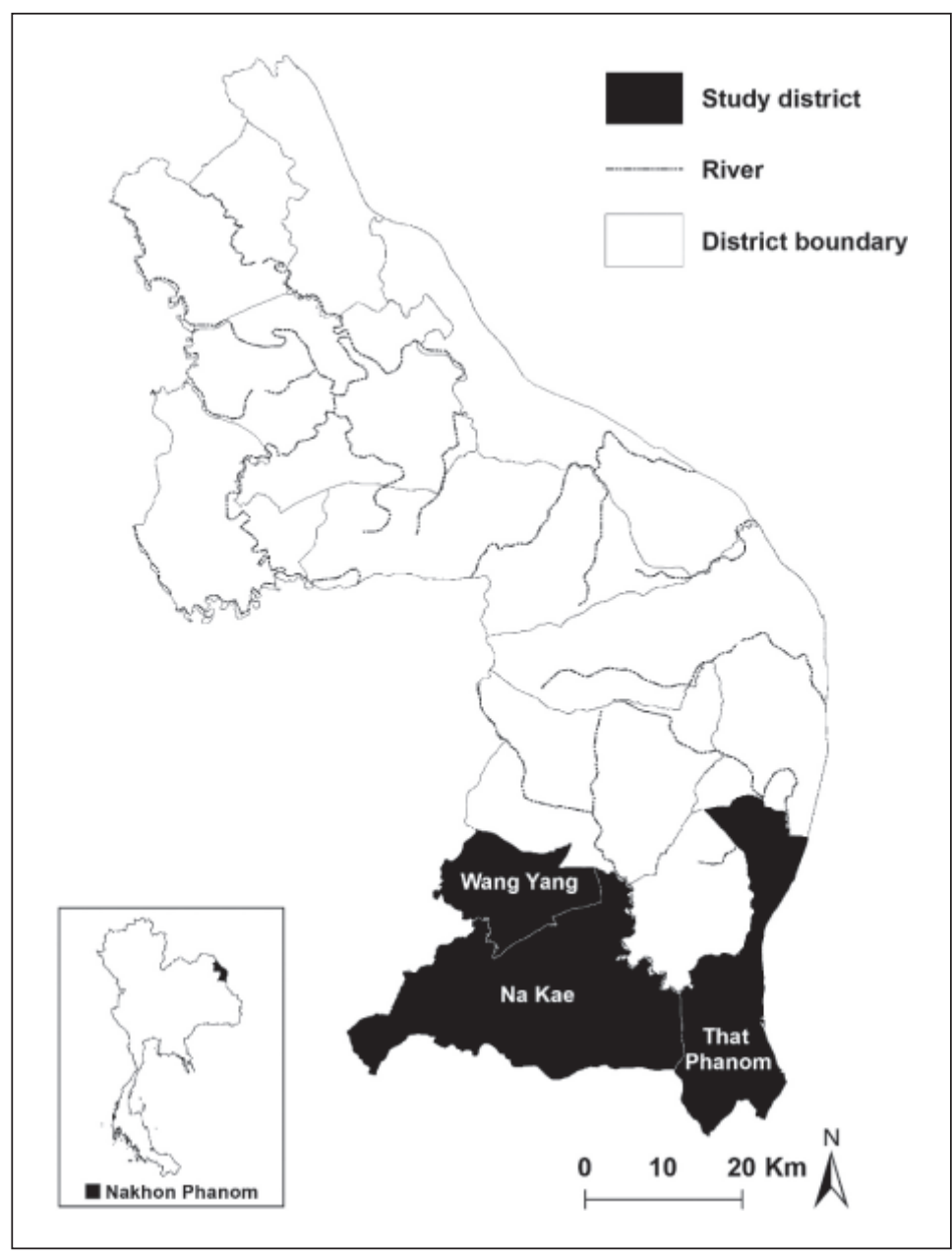

Figure 1. Map showing the three study districts in Nakhon Phanom Province, Thailand.

completed questionnaires were checked for accuracy and completeness.

\section{Sample collection and parasitological examination}

Study participants were invited to provide a single stool sample. Inclusion criteria were individuals who willing to participate in the study, aged $\geq 18$ years old and living in the area for at least six months. After proper instruction, a biohazard zipper bag containing stool container and spatula, labelled with the subject's name and identification number was distributed to each participant. The participants were visited by local health workers at home the following day for collection of the samples. All collected samples were checked for correct labelling and quantity of sample and transported immediately in a cool box to the field laboratory.

Modified thick smears (Chuangchaiya et al., 2019) were prepared after the stool collection using a commercially available Kato-Katz Kit (Department of Helminthology, Faculty of Tropical Medicine, Mahidol University, Bangkok, Thailand). In this study, Kato-Katz thick smears were allowed to clear for 30 minutes before examination under a light microscope (100x magnification). To eliminate bias, each faecal sample was examined by three trained senior medical laboratory technologists who were not informed about the health status and other details of the study participants. All samples were examined on the day of collection. 


\section{Statistical analysis}

Survey data were double entered into Microsoft Excel spreadsheet and crosschecked for errors. Data were processed and analysed using Stata/SE version 13.1 for Windows (StataCorp, TX, USA). Differences in proportions were tested using Chi-squared test or the Fisher's exact test. 95\% confidence intervals (95\% CI) were estimated to provide uncertainty surrounding the point estimates. Univariate logistic regression was performed to identify risk factors for the outcome of $O$. viverrini infection as determined by Kato-Katz thick smear. Odds ratios (OR) and $95 \%$ CI were also computed for the explanatory variables. All variables with a $P<0.05$ from a likelihood ratio test in univariate analyses were entered into a multivariate logistic regression model and stepwise backwards elimination was used to identify the main risk factors for infection. A $P<0.05$ was considered statistically significant.

\section{RESULTS}

\section{Study population and prevalence}

A total of 564 participants (representing approximately $0.3 \%$ of the combined population in the three districts) were screened for intestinal helminth infections out of which 86 (15.2\%; 95\% CI: 12.4 - 18.5) were positive (Table 1). Species distribution included a majority of $O$. viverrini monoinfections ( $\mathrm{n}=73$ ) [12.9\%; 95\% CI: 10.3-15.9], followed by $S$. stercoralis (n = 8) [1.4\%; 95\% CI: $0.6-2.8]$ and Taenia spp. $(\mathrm{n}=2)$ [0.4\%; 95\% CI: 0.0 - 1.3]. Furthermore, three cases of double co-infections were observed comprising two cases of O. viverrinil S. stercoralis (0.4\%; 95\% CI: $0.0-1.3)$ and one case of O. viverrini/Taenia spp. (0.2\%; 95\% CI: $0.0-1.0$ ).

The socio-demographic of the participants and the specific prevalence of $O$. viverrini is summarized in Table 2 . Briefly, the overall prevalence differed significantly $(P=0.022)$ by district: highest in Wang Yang, followed by That Phanom and lowest Na Kae. The prevalence of $O$. viverrini also differed significantly $(P=0.004)$ in male than in female participants. Similarly, with regards to the history of helminth infections, the prevalence differed significantly among those who previously tested positive for other helminth infections $(P<0.001)$ and previously used of anti-helminths $(P<0.001)$.

Table 1. Prevalence of intestinal helminth infections among population $(\mathrm{N}=564)$ living in the three districts in Nakhon Phanom Province, Thailand

\begin{tabular}{lcc}
\hline Intestinal parasitic infection & $\mathrm{n}(\%)$ & $95 \% \mathrm{CI}$ \\
\hline Overall infection & $86(15.2)$ & $12.4-18.5$ \\
Opisthorchis viverrini & $73(12.9)$ & $10.3-15.9$ \\
Strongyloides stercoralis & $8(1.4)$ & $0.6-2.8$ \\
Taenia spp. & $2(0.4)$ & $0.0-1.3$ \\
O. viverrini + S. stercoralis & $2(0.4)$ & $0.0-1.3$ \\
O. viverrini + Taenia spp. & $1(0.2)$ & $0.0-1.0$ \\
\hline
\end{tabular}

n: Number of positive sample; CI: Confidence interval.

Table 2. Socio-demographic of the participants and the specific prevalence of Opisthorchis viverrini in Nakhon Phanom Province, Thailand

\begin{tabular}{|c|c|c|c|c|}
\hline Characteristics & Category & $\begin{array}{c}\text { Sample } \\
\text { examined, } \\
\mathrm{n}(\%)\end{array}$ & $\begin{array}{c}\text { Sample } \\
\text { positive, } \\
\text { n (\%) }\end{array}$ & $P$ value $^{\mathrm{a}}$ \\
\hline \multirow{3}{*}{ District } & $\mathrm{Na} \mathrm{Kae}$ & $178(31.6)$ & $17(9.6)$ & \multirow[t]{3}{*}{$0.022 *$} \\
\hline & That Phanom & $202(35.8)$ & $24(11.9)$ & \\
\hline & Wang Yang & $184(32.6)$ & $35(19.0)$ & \\
\hline \multirow[t]{4}{*}{ Subdistrict } & Kok Sawang & $102(18.1)$ & $4(3.9)$ & \multirow[t]{4}{*}{$<0.001 *$} \\
\hline & $\mathrm{Na} \mathrm{Nat}$ & $100(17.7)$ & $20(20)$ & \\
\hline & Nong Sang & $178(31.6)$ & $17(9.6)$ & \\
\hline & Yot Chat & $184(32.6)$ & $35(19.0)$ & \\
\hline \multirow[t]{2}{*}{ Gender $^{c}$} & Male & $248(44.0)$ & $45(18.2)$ & \multirow[t]{2}{*}{$0.004 * \mathrm{~b}$} \\
\hline & Female & $316(56.0)$ & $31(9.8)$ & \\
\hline
\end{tabular}


Table 2 continued...

\begin{tabular}{|c|c|c|c|c|}
\hline Characteristics & Category & $\begin{array}{l}\text { Sample } \\
\text { examined, } \\
\text { n (\%) }\end{array}$ & $\begin{array}{l}\text { Sample } \\
\text { positive, } \\
\text { n (\%) }\end{array}$ & $P$ value ${ }^{\mathrm{a}}$ \\
\hline Age group ${ }^{c}$ & $\begin{array}{l}18-29 \\
30-39 \\
40-49 \\
50-59 \\
\geq 60\end{array}$ & $\begin{array}{c}23(4.1) \\
58(10.4) \\
155(27.7) \\
196(35.0) \\
128(22.8)\end{array}$ & $\begin{aligned} 0 & (0.0) \\
10 & (17.2) \\
27 & (17.4) \\
26 & (13.3) \\
13 & (10.2)\end{aligned}$ & 0.111 \\
\hline Education level & $\begin{array}{l}\text { No school } \\
\text { Primary } \\
\text { Secondry } \\
\text { Tertiary }\end{array}$ & $\begin{array}{c}12(2.1) \\
439(77.8) \\
90(16.0) \\
23(4.1)\end{array}$ & $\begin{aligned} 0 & (0.0) \\
63 & (14.4) \\
7 & (7.8) \\
6 & (26.1)\end{aligned}$ & 0.051 \\
\hline Marital status ${ }^{c}$ & $\begin{array}{l}\text { Single } \\
\text { Married } \\
\text { divorced/widowed }\end{array}$ & $\begin{aligned} 45 & (8.0) \\
467 & (83.4) \\
49 & (8.7)\end{aligned}$ & $\begin{array}{c}5(11.1) \\
65(13.9) \\
6(12.2)\end{array}$ & 0.838 \\
\hline Household montly income ${ }^{c}$ & $\begin{array}{l}\text { No income } \\
\leq \mathrm{THB} 8000 \\
>\mathrm{THB} 8001\end{array}$ & $\begin{aligned} 226 & (40.2) \\
310 & (55.2) \\
26 & (4.6)\end{aligned}$ & $\begin{array}{c}25(11.1) \\
47(15.2) \\
4(15.4)\end{array}$ & 0.376 \\
\hline Occupation ${ }^{\mathrm{c}}$ & $\begin{array}{l}\text { Farmer/Agriculturist } \\
\text { Labour } \\
\text { Housekeeper } \\
\text { Others }\end{array}$ & $\begin{array}{c}450(79.9) \\
77(13.7) \\
19(3.4) \\
17(3.0)\end{array}$ & $\begin{aligned} 62 & (13.8) \\
12 & (15.6) \\
0 & (0.0) \\
2 & (11.8)\end{aligned}$ & 0.344 \\
\hline History of eating raw fish & $\begin{array}{l}\text { No } \\
\text { Yes }\end{array}$ & $\begin{array}{l}177(31.4) \\
387(68.6)\end{array}$ & $\begin{array}{ll}20 & (11.3) \\
56 & (14.5)\end{array}$ & $0.353^{\mathrm{b}}$ \\
\hline History of faeces examination & $\begin{array}{l}\text { No } \\
\text { Yes }\end{array}$ & $\begin{array}{l}223(39.5) \\
341(60.5)\end{array}$ & $\begin{array}{l}26(11.7) \\
50(14.7)\end{array}$ & $0.377^{\mathrm{b}}$ \\
\hline History of positive helminth & $\begin{array}{l}\text { No } \\
\text { Yes }\end{array}$ & $\begin{array}{l}440(78.0) \\
124(22.0)\end{array}$ & $\begin{array}{c}30(6.8) \\
46(37.1)\end{array}$ & $<0.001 * \mathrm{~b}$ \\
\hline History of taking anti-helminths & $\begin{array}{l}\text { No } \\
\text { Yes }\end{array}$ & $\begin{array}{l}352(62.4) \\
212(37.6)\end{array}$ & $\begin{array}{c}31(8.8) \\
45(21.2)\end{array}$ & $<0.001^{* b}$ \\
\hline Consume alcohol & $\begin{array}{l}\text { No } \\
\text { Yes }\end{array}$ & $\begin{array}{l}318(56.4) \\
246(43.6)\end{array}$ & $\begin{array}{l}37(11.6) \\
39(15.9)\end{array}$ & $0.171^{\mathrm{b}}$ \\
\hline Having domestic animal & $\begin{array}{l}\text { No } \\
\text { Yes }\end{array}$ & $\begin{array}{l}255(45.2) \\
309(54.8)\end{array}$ & $\begin{array}{l}27(10.6) \\
49(15.9)\end{array}$ & $0.083^{\mathrm{b}}$ \\
\hline Type of animalc & $\begin{array}{l}\text { No animal } \\
\text { Dog } \\
\text { Cat } \\
\text { Cat and dog }\end{array}$ & $\begin{aligned} 255 & (46.4) \\
265 & (48.2) \\
10 & (1.8) \\
20 & (3.6)\end{aligned}$ & $\begin{array}{c}27(10.6) \\
46(17.4) \\
1(10.0) \\
1(5.0)\end{array}$ & 0.089 \\
\hline Defecate on water & $\begin{array}{l}\text { No } \\
\text { Yes }\end{array}$ & $\begin{array}{l}229(40.6) \\
335(59.4)\end{array}$ & $\begin{array}{l}27(11.8) \\
49(14.6)\end{array}$ & $0.380^{\mathrm{b}}$ \\
\hline Hampala disparc & $\begin{array}{l}\text { No } \\
\text { Yes }\end{array}$ & $\begin{array}{l}326(59.3) \\
224(40.7)\end{array}$ & $\begin{array}{l}49(15.0) \\
27(12.1)\end{array}$ & $0.379^{\mathrm{b}}$ \\
\hline Osteochilus vittatus ${ }^{\mathrm{c}}$ & $\begin{array}{l}\text { No } \\
\text { Yes }\end{array}$ & $\begin{array}{l}377(68.6) \\
173(31.4) \\
\end{array}$ & $\begin{array}{l}58(15.4) \\
18(10.4)\end{array}$ & $0.143^{\mathrm{b}}$ \\
\hline Barbonymus gonionotus ${ }^{\mathrm{c}}$ & $\begin{array}{l}\text { No } \\
\text { Yes }\end{array}$ & $\begin{array}{ll}266 & (48.4) \\
284 & (51.6)\end{array}$ & $\begin{array}{l}42(15.8) \\
34(12.0)\end{array}$ & $0.217^{\mathrm{b}}$ \\
\hline Anematichthys apogon $^{\mathrm{c}}$ & $\begin{array}{l}\text { No } \\
\text { Yes }\end{array}$ & $\begin{array}{c}468(85.1) \\
82(14.9)\end{array}$ & $\begin{array}{c}67(14.3) \\
9(11.0)\end{array}$ & $0.491^{\mathrm{b}}$ \\
\hline Received info on Opisthorchis & $\begin{array}{l}\text { No } \\
\text { Yes }\end{array}$ & $\begin{aligned} & 19 \\
& 545(3.4) \\
&\end{aligned}$ & $\begin{array}{c}2(10.5) \\
74(13.6)\end{array}$ & $0.999^{\mathrm{b}}$ \\
\hline
\end{tabular}

${ }^{\text {aThe }} P$ values for differences in positivity rates between subcategory were calculated based on Pearson's chi-square test. bFisher's exact test.

${ }^{c}$ Missing data for gender $(\mathrm{n}=4)$, age group $(\mathrm{n}=4)$, marital status $(\mathrm{n}=3)$, income level $(\mathrm{n}=2)$, occupation $(\mathrm{n}=1)$, type of animal $(\mathrm{n}=14), H$. dispar $(\mathrm{n}=14), O$. vittatus $(\mathrm{n}=14), B$. gonionotus $(\mathrm{n}=14)$ and $A$. apogon $(\mathrm{n}=14)$ *Significant difference $P<0.05$. THB: Thai Bhat. 


\section{Factor associated with opisthorchiasis occurrence}

Comprehensive results for all significant co-variables associated with $O$. viverrini infection in univariate analysis $(P<0.05)$ are provided in Table 3 , and these variables were further used to build multivariate models with stepwise forward selection. The final model in multivariate logistic regression showed that being male (adjusted odds ratio [aOR] 1.77 [95\% CI: $1.04-2.99$ ], $P=$ 0.035 ) and tested positive for helminth infections (aOR 8.69 [95\% CI: 4.32 - 17.48], $P<0.001)$ were significantly associated with higher odds of contracting an O. viverrini infection. Nonetheless, the odds of $O$. viverrini infection was significantly lower in those who had previous stool examination (aOR 0.22 [95\% CI: $0.10-0.51$ ], $P=0.001$ ), when compared to those who had not undergone a stool examination.

\section{DISCUSSION}

Although effective anti-helminth drugs and prevention control programmes are in place, intestinal helminth infections remain a critical issue for the rural communities in Thailand. The risk factors commonly associated with these diseases, especially concerning $O$. viverrini, was evaluated in the selected rural population in Nakhon Phanom Province in upper Northeastern Thailand to obtain a better understanding of the underlying reasons behind the tenacious parasitic infections here. This study demonstrated that $O$. viverrini appears to be the highest contributing parasite to the total number of positive helminth infections, followed at a distance by S. stercoralis and Taenia spp. A similar pattern of prominence favouring $O$. viverrini over S. stercoralis and Taenia spp. was also observed in several studies, including by Kaneshiro et al. (2019) that was conducted in Laos; highest for O. viverrini (16.5\%), followed by S. stercoralis (10.8\%) and Taenia spp. (3.3\%). Interestingly, it is not uncommon for communities in Northeastern Thailand and surrounding countries to suffer from double infection by both $O$. viverrini and
S. stercoralis at the same time (Nontasut et al., 2005; Kitvatanachai et al., 2008; Sayasone et al., 2009; Janwan et al., 2011; Kaewpitoon et al., 2019), further highlighting the prevalence of these parasitic infections.

The present study managed to show a significant proportion of $O$. viverrini infection among male respondents. This result was consistent with previous findings where males were more likely to have a higher infection rate when compared with their female counterparts (Boonjaraspinyo et al., 2013; Laoraksawong et al., 2018; Chuangchaiya et al., 2019). The disparity in infection distribution among the genders may be attributed to behavioural factors and socialization patterns that have men consuming more raw fish than females, especially among the rural communities in Thailand (Kaewpitoon et al., 2012; Songserm et al., 2012). Among these habits, consumption of raw or undercooked fish has been attributed as a main contributing factor to the prevalence of $O$. viverrini in the country (Thaewnongiew et al., 2014); this is especially true among those involved in farming and labour-intensive occupation which are typically male-dominated. Convenience, a lack of proper cooking facilities and traditional preparations make it more likely for the fishes to be consumed in raw form, causing an increased risk towards $O$. viverrini infection.

Our study showed that local variation in prevalence was observed between the three districts in Nakhon Phanom Province: highest in Wang Yang, followed by That Phanom and lowest Na Kae. The differences in prevalence between the districts maybe due to their respective distance to the waterbodies where communities procure fish for consumption. A study by Ong et al. (2016) has shown that the distance to waterbody had an impact on how villagers source the fish used in raw fish dishes. Differences in the infections levels in fish are also dependent on the waterbody, thus can affect the risk of human exposure to the infections (Ong et al., 2016). Compare to That Phanom and Na Kae, Wang Yang district is located within the waterway of the Nam Kam River which flows from the neighbouring province of Sakon Nakhon 


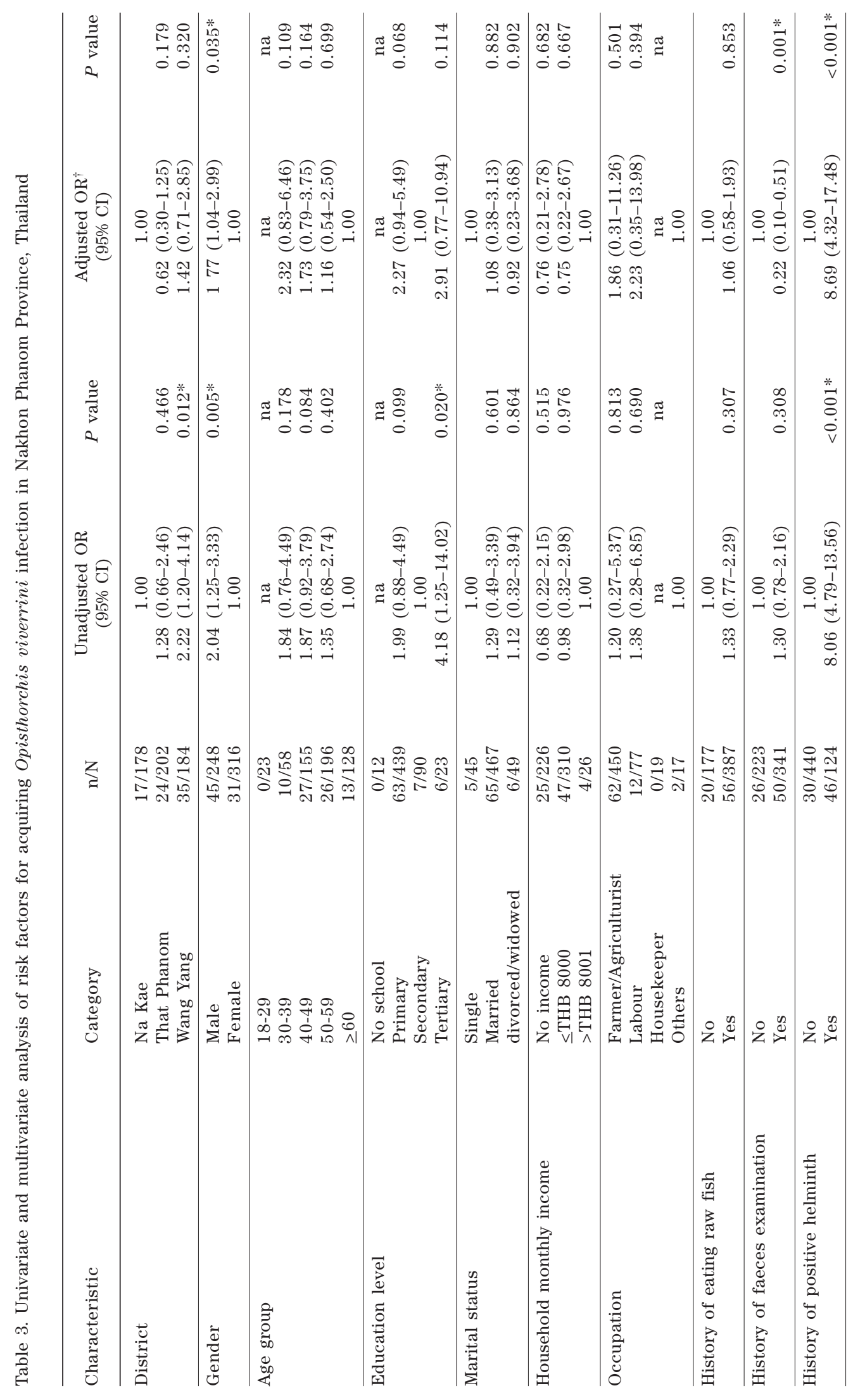




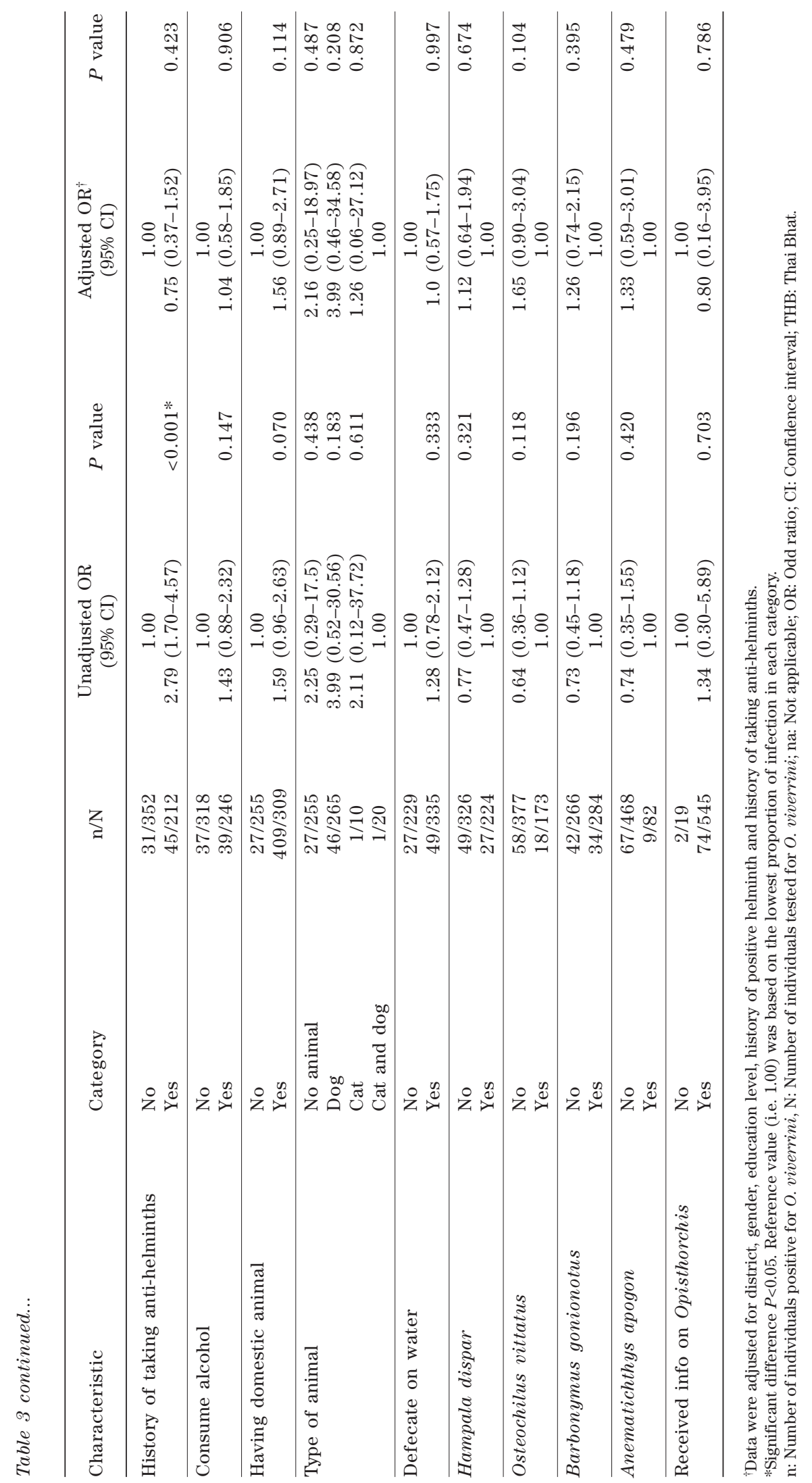


toward downstream of the Mekong River. Our previous study revealed that population lives along the Nam Kam River and its stream with a large freshwater fish stock leads to the regular consumption of raw fish (Chuangchaiya et al., 2019). This phenomenon has been explained by a common process originating from the unidirectional river flow that favours the displacement and downstream dispersion of fish (Blasco-Costa et al., 2013). Thus, the unidirectional river flows supported the existence of a longitudinal gradient in trematode abundance, which increases from upstream-to-downstream along the river. Nevertheless, our study did not examine possible environmental influences such as proximity to different kinds of waterbodies in the relation to the infection. Therefore, comparative multifactorial studies are necessary to gain more insight into the relationship between this environmental factor and the prevalence of $O$. viverrini infection in this area.

The prevalence of $O$. viverrini infection in the present study was not significantly different among age groups. This is in contrast to previous findings where agespecific patterns have been observed for $O$. viverrini infection on other parts of Thailand (Chudthaisong et al., 2015; Nakbun et al., 2018; Chuangchaiya et al., 2019), Laos (Sripa et al., 2011; Forrer et al., 2012) and Cambodia (Yong et al., 2012). Despite the no difference in prevalence among the age groups in our study, people at all ages are at risk of being infected with $O$. viverrini. Cholangiocarcinoma is an Opisthorchisassociated cancer which can take 30-40 years to develop and people infected with $O$. viverrini in their early age may be diagnosed with this cancer during their most productive years of their life, with far reaching negative consequences for their families and the entire communities (Andrews et al., 2008; Steinman et al., 2011). The interrelation of $O$. viverrini infection and age becomes a serious public health issue and requires intergenerational and transgenerational approaches in designing health educations campaign, such as delivering tailored health messages and measures to each specific age group (Phongluxa et al., 2013).

About $40 \%$ of the study population in the present study had not undergone a stool examination prior to this study, which is a common occurrence in nearby regions (Boonjaraspinyo et al., 2013). This may indicate a dearth of access to public health facilities which are aimed at preventive screening and subsequent treatment that potentially aids in the eradication or minimizing $O$. viverrini infection among this rural community. Incidentally, a multivariate analysis of our data indicates that those who underwent a previous stool examination had lower odds of contracting the parasite. It would be assumed that those who had been tested would also have access to the appropriate treatment protocols should they be positive. This would be consistent with the above-mentioned argument that preventive testing does indeed play a crucial role in diminishing the presence of $O$. viverrini in a population.

A significant prevalence of $O$. viverrini infection was found among the respondent who had been tested positive and underwent anti-helminths treatment protocols. In addition to this, the former was also found to be a significant risk factor for contracting the intestinal parasite, almost nine times more likely than the reverse. Both the abovementioned factors are closely related, as those who received treatment would have to be diagnosed first. Although only $22 \%$ of the study population had been previously infected by intestinal helminths, they make up the larger incidence of positive cases, be it in terms of numbers or percentage of cases. This would suggest a low compliance with completion of prescribed dosage and posttreatment follow-ups as well as maintenance of unhealthy habits, primarily the consumption of raw freshwater fish dishes that led to the initial infection. Several studies have also indicated the readily available anti-helminth drug, praziquantel, may be discouraging patients against permanently avoiding this unhealthy dietary habit; with some actively seeking praziquantel treatment upon consumption of traditional raw fish dishes (Grundy-Warr et al., 2012; 
Saengsawang et al., 2016). Despite having a reported cure rate as high as 96 to $100 \%$ (Soukhathammavong et al., 2011) there is a common misconception on the protective effect of praziquantel against reinfection, eventually becoming a contributing risk factor towards the infection by $O$. viverrini (Saengsawang et al., 2013). It has been shown that repeated cycle of infection and treatment may end up increasing the risk of developing cholangiocarcinoma (Charoensuk et al., 2011) as a result of free radical release from inflammatory cells (Sudsarn et al., 2016).

Based on the results obtained, it appears that parasitic helminth infections, especially O. viverrini, remains a pressing issue despite a concentrated effort by the Thailand government. One of the main reasons attributed to this occurrence is the lack of culturally sensitive and focused health education programmes, particularly on the food consumption practices of the local population (Puangsa-art et al., 2006). Proactive measures encouraging and engaging the public to participate in the government programmes aimed at providing awareness on the danger of risk factors associated with $O$. viverrini infection should be intensified. In addition to this, measures to improve sanitation and personal hygiene do go a long way in reducing the prevalence of the disease. This is based on studies where a multipronged approach, combining anthelmintic therapy, sanitation and effective education can bring about a significant reduction and prevent the occurrence of reinfection (Sornmani et al., 1984; Upatham et al., 1988).

A number of caveats should be considered in this study. First, while the convenience sampling approach used in this study was efficient and cost-effective, it has an inherent selection bias. Our survey was conducted mostly during the weekends, meaning that younger adults (i.e. $<30$ years) were disproportionally represented. This group of individuals typically away from home during weekend in our study area. Under-representation of this age group among our samples may likely underestimate the true parasite prevalence in the study areas. Second, due to the imperfect sensitivity of the Kato-Katz technique, the true $O$. viverrini prevalence maybe considerably higher than the rate reported here (Johansen et al., 2020). Third, the survey design did not permit geo-referencing of individual household locations and the complete climate data from each study districts. Therefore, it was not possible to use spatiotemporal analysis to investigate patterns within individual sites. Fourth, the validity of the information provided by respondents in the absence of independent checks or attempts to minimize errors of recall. These kinds or research limitations are difficult to avoid in areas where funding is often largely inadequate.

In conclusion, this study has managed to show a persistent of $O$. viverrini infection in the rural communities in Nakhon Phanom Province. It is hoped that the findings in the present study would provide critical data that can be used towards improving current measures in eradicating of the disease. It is important to create prevention campaigns to persuade people not to consume raw food, but to eat fully cooked dished that are both tasty and free from liver fluke infection. For a healthy community, it is imperative to develop healthy eating behaviours and to teach the people how to protect themselves from the liver fluke infection. For children, educating and exchanging proactive learning in teaching are likely to play an important role in controlling transmission. This should help to adjust the consumption behaviour and personal hygiene in the communities. Efforts to overcome known risk factors, such as a lack of prior testing and previous positive helminths diagnosis, would go a long way in providing long-term mitigation measures, ultimately improving health standards of the local rural communities.

Acknowledgements. We would like to extend our gratitude to the communities and community leaders for their support and participation in the survey. We wish to sincerely thanks all members of the field team. We are grateful to Mr Tawan Kimyong and the director of sub-district Health Promoting Hospital at Fang Daeng (Nakhon Phanom Province) for their assistance in management and logistics throughout the 
study. This study was partially supported by the Geran Galakan Penyelidik Muda (GGPM; Grant no. FF-2018-047) from the Universiti Kebangsaan Malaysia (UKM).

\section{Conflict of interests}

The authors declare no competing financial interests.

\section{REFERENCES}

Andrews, R.H., Sithithaworn, P. \& Petney, T.N. (2008). Opisthorchis viverrini: an underestimated parasite in world health. Trends in Parasitology 24(11): 497-501.

Blasco-Costa, I., Koehler, A.V., Martin, A. \& Poulin, R. (2013). Upstream-downstream gradient in infection levels by fish parasites: a common river pattern? Parasitology 140(2): 266-74.

Bouvard, V., Baan, R., Straif, K., Grosse, Y., Secretan, B., El Ghissassi, F., BenbrahimTalla, L., Guha, N., Freeman, C., Galichet, L. \& Cogliano, V. (2009). A review of human carcinogens - Part B: biological agents. The Lancet Oncology 10(4): 321.

Boonjaraspinyo, S., Boonmars, T., Kaewsamut, B., Ekobol, N., Laummaunwai, P., Aukkanimart, R., Wonkchalee, N., Juasook, A. \& Sriraj. (2013). A crosssectional study on intestinal parasitic infections in rural communities, northest Thailand. The Korean Journal of Parasitology 51(6): 727-734.

Charoensuk, L., Pinlaor, P., Prakobwong, S., Hiraku, Y., Laothong, U., Ruangjirachuporn, W., Yongvanit, P. \& Pinlaor, S. (2011). Curcumin induces a nuclear factorerythroid 2-related factor 2-driven response against oxidative and nitrative stress after praziquantel treatment in liver fluke-infected hamsters. International Jourmal for Parasitology 41(6): 615-626.

Chuangchaiya, S., Laoprom, N. \& Idris, Z.M. (2019). Prevalence and associated risk factors of Opisthorchis viverrini infections in rural communities along the Nam Kam River of Northeastern Thailand. Tropical Biomedicine 36(1): 81-93.
Chudthaisong, N., Promthet, S. \& Bradshaw, P. (2015). Risk factors for Opisthorchis viverrini infection in Nong Khai Province, Thailand. Asian Pacific Journal of Cancer Prevention 16(11): 4593-6.

Conlan, J.V., Khamlome, B., Vongxay, K., Elliot, A., Pallant, L., Sripa, B., Blacksell, S.D., Fenwick, S. \& Andrew Thompson, R.A. (2012). Soil-transmitted helminthiasis in Laos: a community-wide crosssectional study of humans and dogs in a mass drug administration environment. The American Journal of Tropical Medicine and Hygiene 86(4): 624-634.

Forrer, A., Sayasone, S., Vounatsou, P., Vonghachack, Y., Bouakhasith, D., Vogt, S., Glaser, R., Utzinger, J., Akkavong, K. \& Odermatt, P. (2012). Spatial distribution and risk factors for Opisthorchis viverrini infection in southern Lao PDR. PLoS Neglected Tropical Diseases 6(2): e1481.

Grundy-Warr, C., Andrews, R.H., Sithithaworn, P., Petney, T.N., Sripa, B., Laithavewat, L. \& Ziegler, A.D. (2012). Raw attitudes, wetland cultures, life-cycles: sociocultural dynamics relating to Opisthorchis viverrini in the Mekong Basin. Parasitology International 61(1): 65-70. Janwan, P., Intapan, P.M., Thanchomnang, T., Lulitanond, V., Anamnart, W. \& Maleewong, W. (2011). Rapid detection of Opisthorchis viverrini and Strongyloides stercoralis in human fecal samples using a duplex real-time PCR and melting curve analysis. Parasitology Research 109(6): 1593-1601.

Johansen, M.V., Sithithawon, P., Bergquist, R. \& Utzinger, J. (2010). Towards improved diagnosis of zoonotic trematode infections in Southeast Asia. Advances in Parasitology 73: 171-95.

Kaewpitoon, S.J., Ponphimai, S., Pechdee, P, Thueng-in, K., Khiaowichit, J., Meererksom, T., Wakhuwatapong, P., Bukkhunthod, P., Leng, M., Namhong, T., Taweepakdeechot, A., Yardcharoen, N., Srithongklang, W., Keeratibharat, N., Chansangrat, J. \& Kaewpitoon, N. (2019). The prevalence of intestinal helminth 
infection in rural subdistricts of northeastern Thailand. Tropical Biomedicine 36(1): 152-164.

Kaewpitoon, S.J., Rujirakul, R., Ueng-Arporn, N., Matrakool, L., Namwichaisirikul, N., Churproong, S., Wongkaewpothong, P., Nimkuntod, P., Sripa, B. \& Kaewpitoon, N. (2012). Community-based crosssectional study of carcinogenic human liver fluke in elderly from Surin province, Thailand. Asian Pacific Journal of Cancer Prevention 13(9): 4285-4288.

Kaewpitoon, S.J., Sangwalee, W., Kujapun, J., Norkaew, J., Chuatanam, J., Ponphimai, S., Chavengkun, W., Padchasuwan, N., Meererksom, T., Tongtawee, T., Matrakool, L., Panpimanmas, S., Wakkhuwatapong, P. \& Tongtawee, T. (2018). Active screening of gastrointestinal helminth infection in migrant workers in Thailand. Journal of International Medical Research 46(11): 4560-4568.

Kaneshiro, Y., Sourinphoumy, K., Imaizumi, N., Rasaphon, M., Kuba-Miyara, M., Sakihama, S., Guerrero, C.L.H., Nhativong, K., Nonaka, D., Pongvongsa, T., Kobayashi, J., Kounnavong, S. \& Fukushima, T. (2019). Intestinal helminth infections in HIV-infected patients in Savannakhet after establishment of an HIV registration network in Lao People's Democratic Republic. Tropical Medicine and Health 47(1): 14.

Khuntikeo, N., Chamadol, N., Yongvanit, P., Loilome, W., Namwat, N., Sithithaworn, P., Andrews, R.H., Petney, T.N., Promthet, S., Thinkhamrop, K., Tawarungruang, C., Thinkhamrop, B. \& CASCAP Investigators. (2015). Cohort profile: cholangiocarcinoma screening and care program (CASCAP). BMC Cancer 15(1): 459.

Kitvatanachai, S., Boonsilp, S. \& Watanasatitarpa, S. (2008). Intestinal parasitic infections in Srimum suburban area of Nakhon Ratchasima Province, Thailand. Tropical Biomedicine 25(3): 237-242.
Laoraksawong, P., Sanpool, O., Rodpai, R., Thanchomnang, T., Kanarkard, W., Maleewong, W., Kraiklang, R. \& Intapan, P.M. (2018). Current high prevalences of Strongyloides stercoralis and Opisthorchis viverrini infections in rural communities in northeast Thailand and associated risk factors. BMC Public Health 18(1): 940.

Nakbun, S., Thongkrajai, P. \& Nithikathkul, C. (2018). Risk factors for Opisthorchis viverrini infection in Nakhon Phanom, Thailand, where the infection is highly endemic. Asian Biomedicine 12(1): 4551.

Nontasut, P., Muennoo, C., Sa-nguankiat, S., Fongsri, S. \& Vichit, A. (2005). Prevalence of Strongyloides in Northern Thailand and treatment with ivermectin vs albendazole. Southeast Asian Journal of Tropical Medicine and Public Health 36(2): 442.

Ong, X., Wang, Y.C., Sithithaworn, P., Namsanor, J., Taylor, D. \& Laithavewat, L. (2016). Uncovering the pathogenic landscape of helminth (Opisthorchis viverrini) infections: a cross-sectional study on contributions of physical and social environment and healthcare interventions. PLoS Neglected Tropical Diseases 10(12): e0005175.

Phongluxa, K., Xayaseng, V., Vonghachack, Y., Akkavong, K., van Eeuwijk, P. \& Odermatt, P. (2013). Helminth infections in southern Laos: high prevalence and low awareness. Parasites \& Vectors 6(1): 238.

Puangsa-art, S., Yimsamran, S., Buchachart, K., Thanyavanich, N., Wuthisen, P., Rukmanee, P., Maneeboonyang, W., Prommongkol, S. \& Rukmanee, N. (2006). Study on the Ecology of Anopheline Larvae in Malaria Endemic Areas of Tanowsri Canton, Suanphung District, Ratchaburi Province. The Journal of Tropical Medicine and Parasitology 29(2): 56-64. 
Robertson, L.J., van der Giessen, J.W., Batz, M.B., Kojima, M. \& Cahill, S. (2013). Have foodborne parasites finally become a global concern? Trends in Parasitology 29(3): 101-103.

Saengsawang, P., Promthet, S. \& Bradshaw, P. (2013). Infection with Opisthorchis viverrini and use of praziquantel among a working-age population in northeast Thailand. Asian Pacific Journal of Cancer Prevention 14(5): 2963-2966.

Saengsawang, P., Promthet, S. \& Bradshaw, P. (2016). Reinfection by Opisthorchis viverrini after treatment with praziquantel. Asian Pacific Journal of Cancer Prevention 17(2): 857-862.

Sayasone, S., Vonghajack, Y., Vanmany, M., Rasphone, O., Tesana, S., Utzinger, J., Akkhavong, K. \& Odermatt, P. (2009). Diversity of human intestinal helminthiasis in Lao PDR. Transactions of the Royal Society of Tropical Medicine and Hygiene 103(3): 247-254.

Sithithaworn, P., Andrews, R.H., Van De, N., Wongsaroj, T., Sinuon, M., Odermatt, P., Nawa, Y. \& Sripa, B. (2012). The current status of opisthorchiasis and clonorchiasis in the Mekong Basin. Parasitology International 61(1): 10-16.

Songserm, N., Promthet, S., Wiangnon, S. \& Sithithaworn, P. (2012). Prevalence and co-infection of intestinal parasites among Thai rural residents at high-risk of developing cholangiocarcinoma: a cross-sectional study in a prospective cohort study. Asian Pacific Journal of Cancer Prevention 13(12): 6175-6179.

Sornmani, S., Vivatanasesth, P., Impand, P., Phatihatakorn, W., Sitabutra, P. \& Schelp, F. (1984). Infection and re-infection rates of opisthorchiasis in the water resource development area of Nam Pong project, Khon Kaen Province, northeast Thailand. Annals of Tropical Medicine \& Parasitology 78(6): 649-656.

Soukhathammavong, P., Odermatt, P., Sayasone, S., Vonghachack, Y., Vounatsou, P., Hatz, C., Akkhavong, K. \& Keiser, J. (2011). Efficacy and safety of mefloquine, artesunate, mefloquine-artesunate, tribendimidine, and praziquantel in patients with Opisthorchis viverrini: a randomised, exploratory, open-label, phase 2 trial. The Lancet Infectious Diseases 11(2): 110-118.

Sripa, B., Bethony, J.M., Sithithawon, P., Kaewkes, S., Mairiang, E., Loukas, A., Mulvenna, J., Laha, T., Hotez, P.J. \& Brindley, P.J. (2011). Opisthorchiasis and Opisthorchis-associated cholangiocarcinoma in Thailand and Laos. Acta Tropica 120(1): S158-68.

Sripa, B., Kaewkes, S., Sithithaworn, P., Mairiang, E., Laha, T., Smout, M., Pairojkul, C., Bhudisawasdi, V., Tesana, S., Thinkamrop, B., Bethony, J.M., Loukas, A. \& Brindley, P.J. (2007). Liver fluke induces cholangiocarcinoma. PLoS Medicine 4(7): e201.

Sripa, B., Tangkawattana, S., Laha, T., Kaewkes, S., Mallory, F.F., Smith, J.F. \& Wilcox, B.A. (2015). Toward integrated opisthorchiasis control in northeast Thailand: the Lawa project. Acta Tropica 141(Pt B): 361-367.

Steinmann, P., Utzinger, J., Du, Z.W., Jiang, J.Y., Chen, J.X., Hattendorf, J., Zhou, H. \& Zhou, X.N. (2011). Efficacy of singledose and triple-dose albendazole and mebendazole against soil-transmitted helminths and Taenia spp.: a randomized controlled trial. PLoS One 6(9): e25003.

Sudsarn, P., Boonmars, T., Ruangjirachuporn, W., Namwat, N., Loilome, W., Sriraj, P., Aukkanimart, R., Nadchanan, W. \& Jiraporn, S. (2016). Combination of praziquantel and aspirin minimizes liver pathology of hamster Opisthorchis viverrini infection associated cholangiocarcinoma. Pathology \& Oncology Research 22(1): 57-65.

Suwannatrai, A., Saichua, P. \& Haswell, M. (2018). Epidemiology of Opisthorchis viverrini infection. Advances in Parasitology 101: 41-67.

Thaewnongiew, K., Singthong, S., Kutchamart, S., Tangsawad, S., Promthet, S., Sailugkum, S. \& Wongba, N. (2014). Prevalence and risk factors for Opisthorchis viverrini infections in upper Northeast Thailand. Asian Pacific Journal and Cancer Prevention 15(16): 6609-6612. 
Tun, A., Myat, S.M., Gabrielli, A.F. \& Montresor, A. (2013). Control of soil transmitted helminthiasis in Myanmar: results of 7 years of deworming. Tropical Medicine \& International Health 18(8): 1017-1020.

Upatham, E., Viyanant, V., Brockelman, W., Kurathong, S., Lee, P. \& Kraengraeng, R. (1988). Rate of re-infection by Opisthorchis viverrini in an endemic northeast Thai community after chemotherapy. International Journal for Parasitology 18(5): 643-649.
Yong, T.S., Shin, E.H., Chai, J.Y., Sohn, W.M. Eom, K.S., Lee, D.M., Park, K., Jeoung, H.G., Hoang, E.H., Lee, Y.H., Woo, H.J., Lee, J.H., Kang, S.I., Cha, J.K., Lee, K.H., Yoon, C.H., Sinuon, M. \& Socheat, D. (2012). High prevalence of Opisthorchis viverrini infection in a riparian population in Takeo Province, Cambodia. The Korean Journal of Parasitology 50(2): $173-6$ 